\title{
Microfabrication of Si by KOH Etchant Using Etching Mask Amorphized by Ar Ion Beam
}

\author{
Mina Sato, Mie Tohnishi, and Akihiro Matsutani \\ Semiconductor and MEMS Processing Division, Open Facility Center, Tokyo Institute of Technology, \\ 4259 Nagatsuta, Yokohama 226-8503, Japan
}

(Received November 26, 2021; accepted December 28, 2021)

Keywords: Si, amorphous, $\mathrm{KOH}$, wet chemical etching, ion beam, microfabrication

We demonstrate the microfabrication of $\mathrm{Si}$ by $\mathrm{KOH}$ wet etching using a mask pattern amorphized by an ion beam as an etching mask. An electron cyclotron resonance ion shower system was used as an ion beam source of 100 to $1000 \mathrm{eV}$ energy. We succeeded in fabricating an etching mask that can etch a $\mathrm{Si}(110)$ substrate wafer to a depth of $3.7 \mu \mathrm{m}$ by amorphizing the Si surface at an ion energy of $400 \mathrm{eV}$. In addition, we made microfluidic devices and single-cell isolation chips using the proposed microfabrication technique. We believe that the proposed technique will be useful for the microfabrication of Si-based microfluidic devices and biochips.

\section{Introduction}

In semiconductor processes, wet chemical etching and dry etching techniques are widely used for 3D microfabrication. Generally, the mechanism of wet chemical etching using, for example, hydrofluoric-nitric acid solutions is simpler than that of dry etching, and the etching profile is isotropic. ${ }^{(1,2)}$ However, when a Si crystal surface is etched with a $\mathrm{KOH}$ solution, it is possible to fabricate a 3D structure composed of specific crystal planes due to the crystal orientation dependence of the etching rate. In such anisotropic etching, microstructures such as bridges and $\mathrm{V}$-shaped grooves can be fabricated by appropriately selecting the crystalline plane of the Si substrate and the etching mask area. ${ }^{(3-6)}$ The anisotropic etching of Si crystal using $\mathrm{KOH}$ wet etching has excellent uniformity and reproducibility, and can be widely applied to the manufacture of MEMS devices. ${ }^{(7-10)}$ In the anisotropic wet etching of $\mathrm{Si}, \mathrm{SiO}_{2}$ or $\mathrm{Si}_{3} \mathrm{~N}_{4}$ is generally used as an etching mask. In many cases, it is necessary to remove the etching mask material (e.g., $\mathrm{SiO}_{2}$ ) with a solution such as $\mathrm{HF}$ after $\mathrm{Si}$ wet etching. When $\mathrm{Si}$ itself is used as an etching mask material, a technique that combines amorphization processing by a friction force microscope or focused ion beam (FIB) and chemical wet etching can be used.(11-15) A singlecrystal silicon surface irradiated with $30 \mathrm{keV} \mathrm{Ga}^{+}$by an FIB changes from crystalline to amorphous. Since the amorphized area is resistant to $\mathrm{KOH}$ etchant, it can be used as an etching mask. However, the area amorphized by the FIB process is very small and only on the order of $100 \mu \mathrm{m}^{2}$. Therefore, we employed a low-energy ion beam using an electron cyclotron resonance

*Corresponding author: e-mail: sato.m.ar@m.titech.ac.jp

https://doi.org/10.18494/SAM3747 
(ECR) ion source as a means of large-area amorphization of a Si crystal surface. The beam diameter of the ECR ion source was about 10 to $200 \mathrm{~mm}$ and a wider area can be amorphized. In addition, in the amorphization process using the ECR ion source, the ion energy, process pressure, gas flow rate, and ion incident angle can be controlled independently. Therefore, it is also advantageous for controlling the depth of the amorphized region.

In this paper, we report the experimental results of $\mathrm{Si}$ amorphized by Ar ion irradiation using an ECR ion source as a mask for $\mathrm{KOH}$ etching. We also describe the application of this technique to the fabrication of a microchannel and a single-cell isolation chip.

\section{Experimental Setup}

Figure 1 shows a schematic diagram of the ECR ion shower system (Elionix EIS-200ER) used in this experiment. The generated ions in the plasma are accelerated through the two grids with many holes and irradiated to the sample. ${ }^{(16-18)}$ In this system, the ion energy can be controlled independently of the other parameters. The ion current density can be measured with a Faraday cup. The ion incident angle can be changed by tilting the sample stage. We used Ar as a gas source of plasma. We used a $\mathrm{Si}(100)$ substrate of $15 \times 15 \mathrm{~mm}^{2}$ size and a $\mathrm{Si}(110)$ substrate of $10 \mathrm{~mm}$ length on each side as samples. These $\mathrm{Si}$ wafers were cleaned with buffered hydrofluoric acid (BHF) before the photolithography processes. The mask pattern was prepared on $\mathrm{Si}$ substrates with a photoresist (AZ5214E). After the ion irradiation, the photoresist was removed with acetone. Then, the sample was etched with a $45 \mathrm{wt} \% \mathrm{KOH}$ aqueous solution at 26 ${ }^{\circ} \mathrm{C}$. The height of the fabricated structure was measured with a stylus surface profiler (Veeco, Dektak150).

\section{Experimental Results and Discussion}

The thickness of the amorphized region on the Si surface is associated with the penetration depth of Ar ions into the $\mathrm{Si}$ substrate. We expected that the amorphous region would be sufficiently thin to require TEM observation. Therefore, we proposed $h_{s}$, schematically defined in Fig. 2, as a value to evaluate the $\mathrm{KOH}$ etching resistance. When a Si mask region irradiated with Ar ions is etched by $\mathrm{KOH}$ etchant, the height of the etched structure increases with

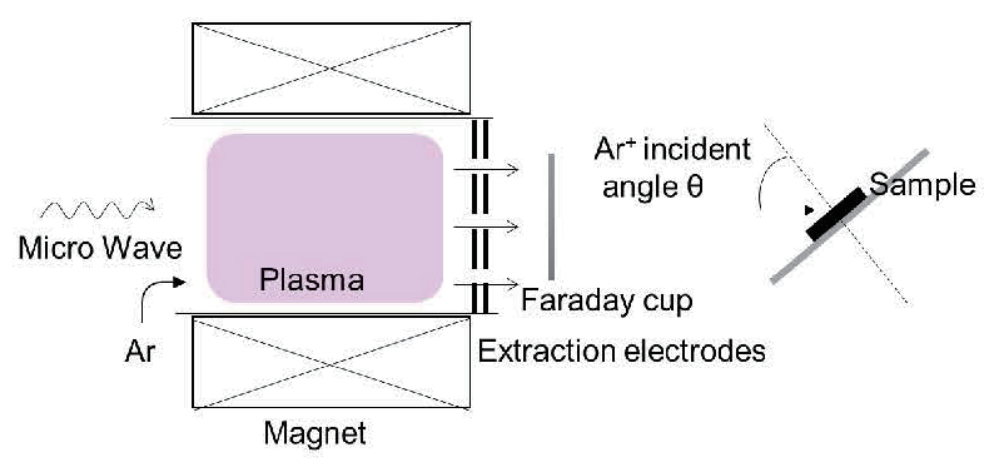

Fig. 1. (Color online) Schematic diagram of ECR ion shower system used in this experiment. 

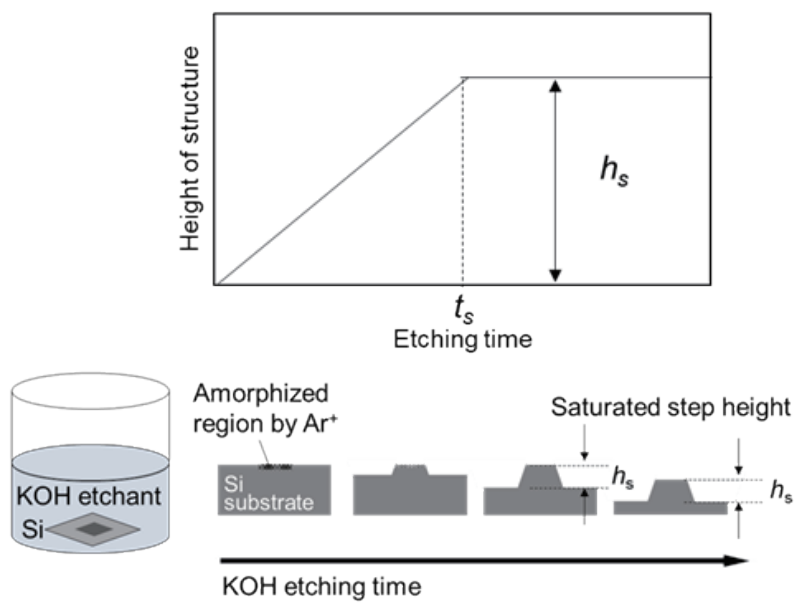

Fig. 2. Schematic diagram of $h_{s}$, the value used to evaluate the etching resistance.

increasing etching time. After the etching mask region disappears, the height of the etched microstructure remains constant, which we defined as $h_{s}$ (saturated step height). We also defined $t_{s}$ as a time when the amorphized mask disappears. Thereby, a larger $h_{s}$ indicates greater selectivity of the ion-irradiated area against the $\mathrm{KOH}$ etching rate. In the following, we describe the $\mathrm{Ar}^{+}$incident angle, $\mathrm{Ar}^{+}$ion dose, and $\mathrm{Ar}^{+}$ion energy dependences of $h_{s}$.

In this experiment, the sputtering of $\mathrm{Si}$ atoms occurs at the same time as the formation of the amorphous layer on the surface of the Si substrate under Ar ion irradiation. However, when the dose is $1 \times 10^{15}$ ions $/ \mathrm{cm}^{2}$ or more, the thickness of the formed amorphous layer is constant. ${ }^{(19)}$ The thickness sputtered at a dose of $1 \times 10^{15}$ ions $/ \mathrm{cm}^{2}$ is sufficiently smaller than the thickness of the amorphous layer.

\section{1 $\quad \mathrm{Ar}^{+}$incident angle dependence of $h_{s}$}

Figure 3 shows the relation between the ion incident angle and $h_{s}$, where the ion incident angle was changed from 0 to $90^{\circ}$. The Si substrate was implanted with $400 \mathrm{eV} \mathrm{Ar}^{+}$ions at a dose of $3 \times 10^{17}$ ions $/ \mathrm{cm}^{2}$. When the incident angle of $\mathrm{Ar}^{+}$was $0^{\circ}, h_{s}$ was more than $1 \mu \mathrm{m}$. It is considered that a larger $h_{s}$ was obtained because the amorphized layer acting as an etching mask became thicker due to the channeling effect. ${ }^{(20)}$ However, when the incident angle was $7^{\circ}$ or more, $h_{s}$ decreased as the ion incident angle increased. The ECR ion shower system used in this experiment has an ion beam divergence angle of approximately 5 degrees. In other words, even when $\mathrm{Ar}$ ions were irradiated parallel to the surface of the Si substrate (corresponding to an incident angle of $90^{\circ}$ ), the $\mathrm{Ar}$ ion beam irradiates to the $\mathrm{Si}$ substrate slightly. This thin amorphized surface layer acts as an etching mask.

The scanning electron microscopy (SEM) image inset in Fig. 3 is that of a microstructure fabricated with $120 \mathrm{~min}$ of $\mathrm{KOH}$ etching, with the mask pattern irradiated at $\mathrm{an}^{+}{ }^{+}$incident angle of $0^{\circ}$ and a dose of $3 \times 10^{17} \mathrm{ions} / \mathrm{cm}^{2}$. The quantitative observation of the undercut of the convex corners after $\mathrm{KOH}$ etching by our SEM was difficult. It is known that the etching rate of 


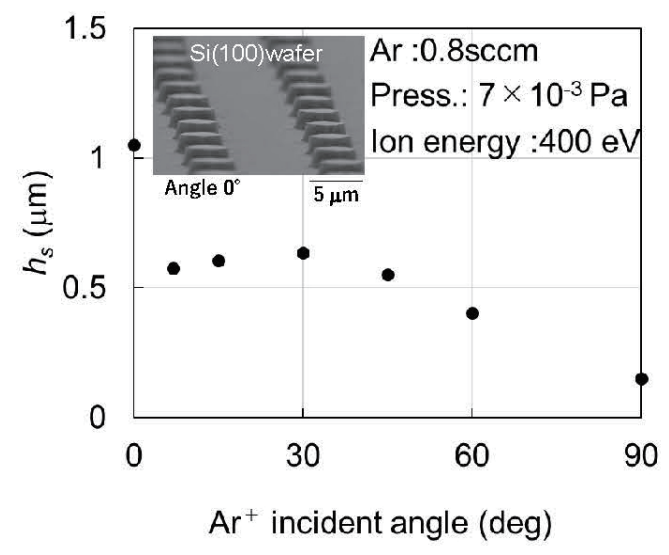

Fig. 3. Relation between the ion incidence angle and $h_{s}$. The inset is an SEM image of a microstructure fabricated at an $\mathrm{Ar}^{+}$incident angle of $0^{\circ}$.

the Si (111) surface is very small compared with that of the Si (100) surface. The etching rate ratio $\mathrm{Si}$ (100): $\mathrm{Si}$ (111) is approximately 100 to 1000 : 1 , and the etching depth of the structure fabricated in this experiment is $1 \mu \mathrm{m}$, so the undercut is estimated to be about $1-10 \mathrm{~nm}$.

\subsection{Ion dose dependence of $h_{s}$}

Figure 4 shows the relation between the ion dose and $h_{s}$, where the Si substrate was implanted with $\mathrm{Ar}^{+}$of $400 \mathrm{eV}$ at an angle of $7^{\circ}$ and the ion dose was controlled via the irradiation time. It was found that $h_{s}$ is almost constant in the dose range of $3 \times 10^{16}$ to $9 \times 10^{17} \mathrm{ions} / \mathrm{cm}^{2}$. This result is the same as the result reported in Ref. 19. Ishii et al. have explained that the thickness of the amorphous layer is saturated at a dose of $1 \times 10^{15} \mathrm{ions} / \mathrm{cm}^{2}$ or more in their experiment. Therefore, $h_{s}$ was independent of the ion dose.

\subsection{Ion energy dependence of $h_{s}$}

Figure 5(a) shows the relation between the ion energy and $h_{s}$. The sample was irradiated by $\mathrm{Ar}^{+}$ions in the range of ion energies from 100 to $1000 \mathrm{eV}$ at a dose of $3 \times 10^{17} \mathrm{ions} / \mathrm{cm}^{2}$ and the incident angle of the ions was $7^{\circ} . h_{s}$ increased with increasing ion energy. This phenomenon is considered to result in the depth of the irradiated area increasing with increasing ion energy and the formation of a thicker amorphized layer. To estimate the thickness of the amorphized layer, we calculated the depth range of ions $\left(R_{p}\right)$ in the Si using the simulation program SRIM 2013 (Stopping and Range of Ions in Matter) by the Monte Carlo method. ${ }^{(21)}$ This SRIM simulation program can be used to calculate $R_{p}$ only at an ion incidence angle of $0^{\circ}$. In this experiment, the sample substrate was tilted $7^{\circ}$ to suppress the channeling effect.

The calculated range $R_{p}$ of $\mathrm{Ar}^{+}$ions in the Si substrate is shown on the right axis of Fig. 5(a). It has been reported that the distribution of defects (corresponding to the amorphized layer) in the Si crystal is shallower than that of irradiated ions. ${ }^{(19,22,23)}$ Therefore, the thickness of the 


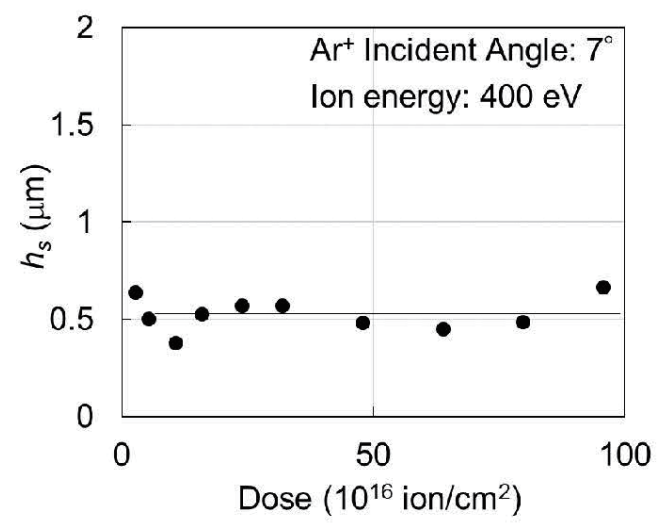

Fig. 4. Relation between Ar ion dose and $h_{s}$.

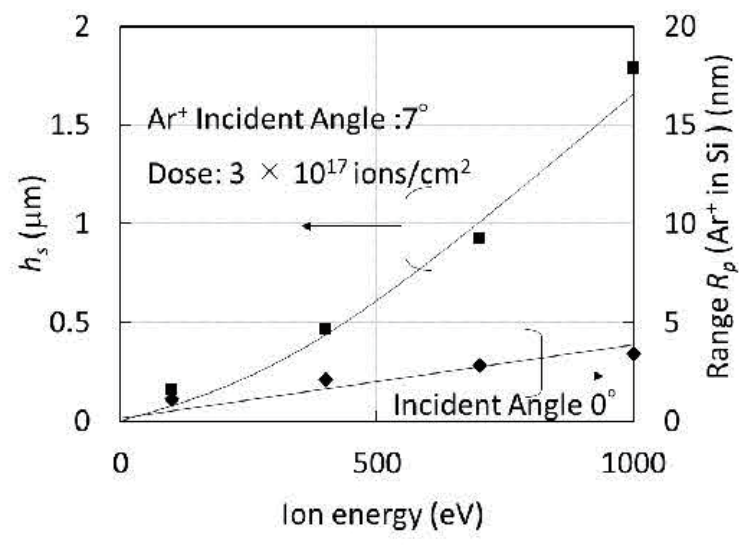

(a)

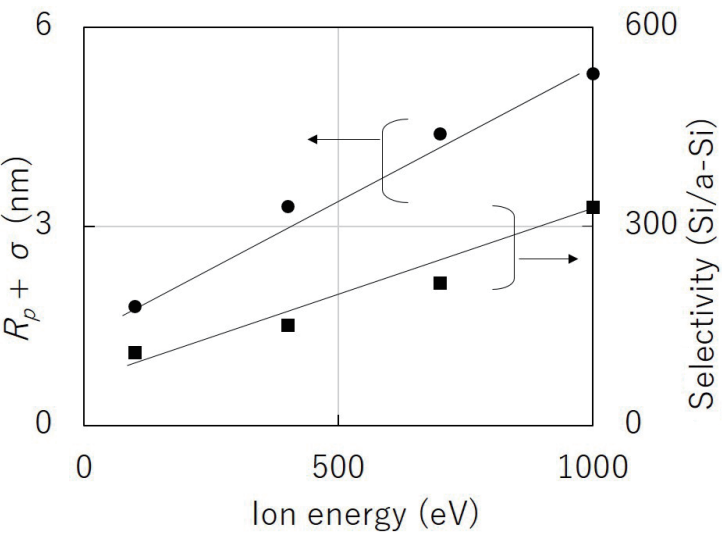

(b)

Fig. 5. (a) $h_{s}$ (left axis) and stopping range (right axis) with respect to ion energy. (b) $R_{p}+\sigma$ (left axis) and selectivity (right axis) with respect to ion energy.

amorphized layer can be estimated as the sum of $R_{p}$ and the maximum straggling depth $\sigma$. Figure 5(b) shows the relation between the ion energy and the sum of $R_{p}$ and $\sigma$. In this simulation, the maximum thickness of the amorphized layer of $\mathrm{Si}$ at the ion energy of $400 \mathrm{eV}$ was estimated to be $3.3 \mathrm{~nm}$. In addition, the amorphized layer in the $\mathrm{Ar}^{+}$-irradiated area could be used as a mask for 30 min $\mathrm{KOH}$ etching. This time $t_{s}$ can be calculated from the $\mathrm{KOH}$ etching rate and $h_{s}$ as shown in Fig. 2. The etching rate of Si by $\mathrm{KOH}$ etching was $16.6 \mathrm{~nm} / \mathrm{min}$. Therefore, the selectivity of the etching rates was estimated to be 150 . The estimated selectivity is shown on the right axis of Fig. 5(b). This selectivity increases with increasing ion energy. As the reason for this, the larger the ion energy, the lateral straggling also increases. As a result, we presume that a highly dense amorphous layer was formed and the resistance to $\mathrm{KOH}$ etching was improved. 


\subsection{Microfabrication of $\mathrm{Si}(110)$ substrate}

In the above experiments, we used a Si (100) substrate as a sample. However, the Si (100) plane has a high apparent areal density of atoms when viewed from the substrate surface. Therefore, we attempted to implant $\mathrm{Ar}^{+}$of $400 \mathrm{eV}$ energy at an angle of $0^{\circ}$ into the $\mathrm{Si}$ (110) substrate to use the channeling effect. Dose was $5 \times 10^{16}$ ions $/ \mathrm{cm}^{2}$. Figure 6 shows a crosssectional SEM image of the fabricated microstructure of the $\mathrm{Si}(110)$ substrate after $\mathrm{KOH}$ etching for $120 \mathrm{~min}$. The height of the structure was $3.5 \mu \mathrm{m}$. After taking this SEM image, we carried out further $\mathrm{KOH}$ etching and confirmed that $h_{s}$ was $3.7 \mu \mathrm{m}$. In other words, the amorphous layer remains as an etching mask in Fig. 6. The $\mathrm{KOH}$ etching rate of the (110) plane was $29.4 \mathrm{~nm} / \mathrm{min}$ in this experiment. It was verified that the mask amorphized using an Ar ion beam is also effective for the $\mathrm{KOH}$ etching of a $\mathrm{Si}(110)$ substrate.

\section{Application to Single-cell Isolation Plates and Microfluidic Device}

We applied this etching technique to fabricate a single-cell isolation plate comprising an array of microenclosures made from a structure of micropillars. ${ }^{(24,25)}$ The structure used for cell isolation was designed by adjusting the height and gap of micropillars according to the size of the cells. We used yeast (S. cerevisiae) cells with a size of approximately $3 \mu \mathrm{m}$ as a sample. For single-cell isolation, the size of each microenclosure should be $8 \times 8 \mu \mathrm{m}^{2}$ with a space of about 1 $\mu \mathrm{m}$ between micropillars as reported in Ref. 25. In this experiment using $\mathrm{KOH}$ etching, it was necessary to consider the effect of anisotropic etching due to the crystal orientation of Si. Thus, we designed the width of each microenclosure to be $10 \mu \mathrm{m}$ and the space between the pillars to be $2 \mu \mathrm{m}$ on the Si (110) substrate. The height of the pillar was $1.3 \mu \mathrm{m}$. Figure 7(a) shows an optical microscopy image of the cells captured in a microenclosure array. An array of threedimensional structure was fabricated on the Si (110) substrate. We used a maskless exposure equipment (resolution: $3 \mu \mathrm{m}$ ) using DMD for resist exposure. Although the CAD pattern was of square shape, owing to the limitation of equipment performance, the corners of the formed resist pattern were formed as a rounded shape and the etching shape is hexagon-like. The fabricated

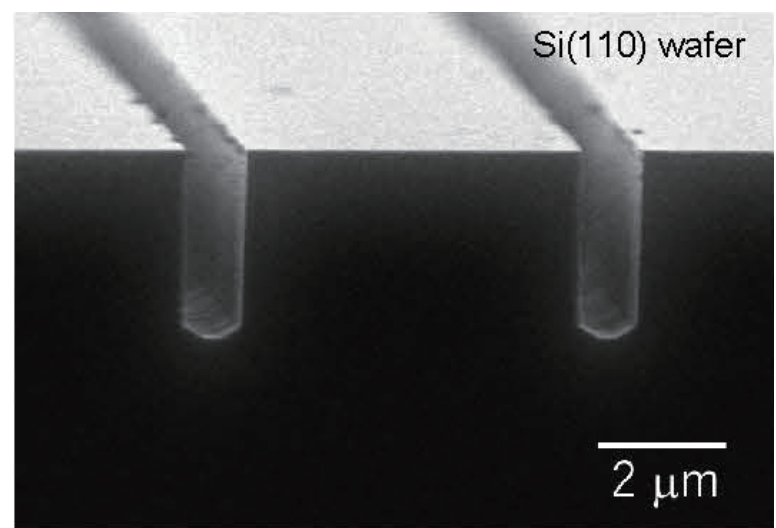

Fig. 6. SEM image of microstructure fabricated on Si (110) substrate. 


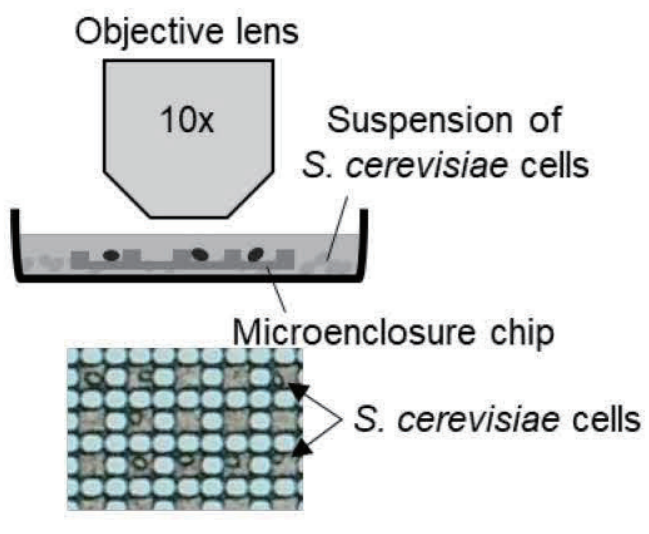

(a)

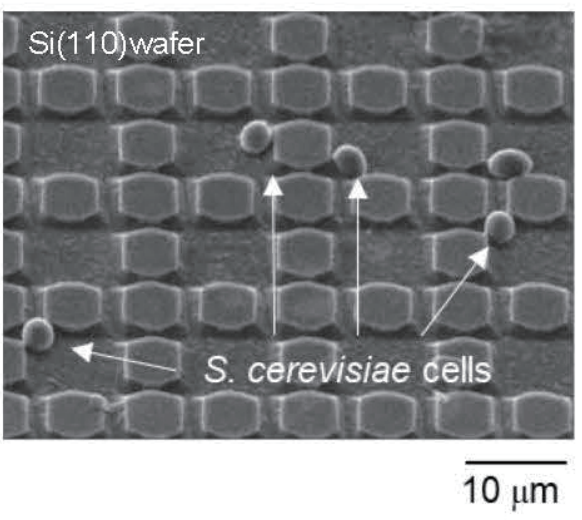

(b)

Fig. 7. (Color online) (a) Schematic diagram of observation with an optical microscope and optical microscopy image. (b) SEM image of single cells captured in microenclosure array.

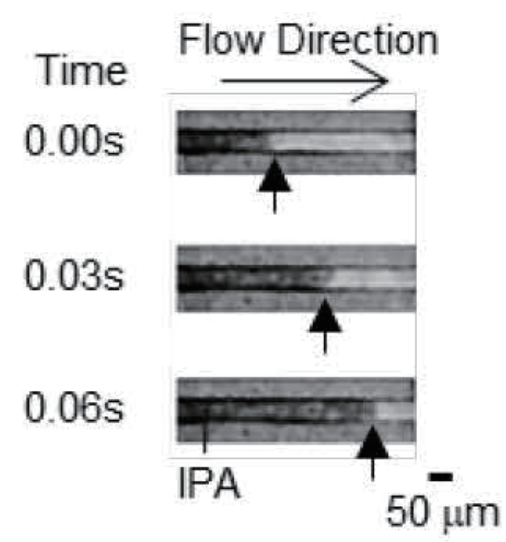

Fig. 8. Optical microscopy images taken during liquid flow test of fabricated microchannel.

microenclosure chip was placed in a plastic dish and a suspension of $S$. cerevisiae cells was poured into the dish to a depth of $2 \mathrm{~mm}$. Then the cells were observed by epi-illumination with a $10 \times$ objective lens. The isolation of single $S$. cerevisiae cells was achieved using this fabricated chip. Next, the suspension of $S$. cerevisiae cells was added dropwise on the chip and allowed to dry. Figure 7(b) shows an SEM image of isolated single $S$. cerevisiae cells. The cells were individually separated by the microenclosure because they could not pass through the spaces between the micropillars.

We also applied the $\mathrm{KOH}$ etching technique to fabricate a microfluidic device. First, a groove with a width of $50 \mu \mathrm{m}$ and a depth of $3 \mu \mathrm{m}$ was fabricated on a Si (110) substrate. Next, a polydimethylsiloxane (PDMS) sheet was bonded to the grooved Si substrate top by solid-source $\mathrm{H}_{2} \mathrm{O}$ plasma treatment. ${ }^{(26)}$ After that, we flowed isopropyl alcohol (IPA) into the microchannel by capillary force. Figure 8 shows optical microscopy images taken during the liquid flow test. It is found that IPA flowed in the microchannel. 
From the above results, we demonstrated that this microfabrication technique of $\mathrm{Si}$ by $\mathrm{KOH}$ etching using an etching mask amorphized by an Ar ion beam can be applied to the fabrication of, for example, microfluidic devices and single-cell isolation chips.

\section{Conclusions}

We have demonstrated a technique for improving the etching resistance of $\mathrm{KOH}$ by amorphizing a wide area of a Si surface and a thin surface layer by $\mathrm{Ar}^{+}$beam irradiation using ECR plasma. The etching resistance of the amorphized region against the $\mathrm{KOH}$ wet etching of $\mathrm{Si}$ improved with increasing ion energy. The thickness of the amorphized layer was related to the depth of ion penetration into the Si substrate and was estimated by simulation to be approximately $3 \mathrm{~nm}$ at an ion energy of $400 \mathrm{eV}$. The etching selectivity of the $\mathrm{KOH}$ etching rate of the $\mathrm{Si}$ substrate and the amorphized mask was 100 to 300, allowing the mask to be used as an etching mask. In addition, we applied this technique using amorphized etching masks and $\mathrm{KOH}$ wet etching to device fabrication (a microenclosure array for single-cell isolation and a microchannel). We have confirmed that this technique can also be employed using sputtering equipment and a desktop coater. We believe that the proposed process is a highly versatile technology because simple plasma equipment can be used.

\section{Acknowledgments}

This work was the result of using research equipment shared in the MEXT Project for the remote public utilization of advanced research infrastructure (Program for Supporting Construction of Core Facilities) Grant Number JPMXS0440200021.

\section{References}

1 J. W. Cobum and Harold F. Winters: J. Vac. Sci. Technol. 16 (1979) 391.

2 H. Robbins and B. Schwartz: J. Electrochem. Soc. 107 (1960) 108.

K. Naraoka: Oyo Buturi 53 (1984) 877 (in Japanese).

4 F. Shimokawa: J. Jpn. Soc. Precis. Eng. 77 (2011) 162 (in Japanese).

5 D. B. Lee: J. Appl. Phys. 40 (1969) 4569.

6 K. E. Bean: IEEE Trans Electron Devices 25 (1978) 1185.

7 K. Sato, M. Shikida, Y. Matsushima, T. Yamashiro, K. Asaumi, Y. Iriye, and M. Yamamoto: Sens. Actuators, A 64 (1998) 87.

8 K. Sato, M. Shikida, T. Yamashiro, M. Tsunekawa, and S. Ito: Sens. Actuators 73 (1999) 122.

9 M. Shikida, K. Sato, K. Tokoro, and D. Uchikawa: Sens. Actuators 80 (2000) 179.

10 M. Shikida: J. Surf. Finish. Soc. Jpn. 59 (2008) 84 (in Japanese).

11 B.Schmidt, L. Bischoff, and J. Teichert: Sens. Actuators A 61 (1997) 369.

12 N. Kawasegi, N. Morita, S. Yamada, N. Takano, T. Oyama, and K. Ashida: Trans. Jpn. Soc. Mech. Eng. C. 70 (2004) 2533 (in Japanese).

13 N. Kawasegi, K. Shibata, N. Morita, K. Ashida, J. Taniguchi, and I. Miyamoto: Trans. Jpn. Soc. Mech. Eng. C. 70 (2004) 2541 (in Japanese).

14 N. Kawasegi, N. Morita, S. Yamada, N. Takano, T. Oyama, K. Ashida, and J. W. Park: Trans. Jpn. Soc. Mech. Eng. C. 71 (2005) 2035 (in Japanese).

15 N. Kawasegi, T. Fukase, N. Morita, K. Ashida, J. Taniguchi, I. Miyamoto, and S. Momota: Trans. Jpn. Soc. Mech. Eng. C. 74 (2008) 3056 (in Japanese).

16 T. Masuzawa: J. Jpn. Soc. Precis. Eng. 55 (1989) 270 (in Japanese). 
17 T. Masuzawa, I. Tsuchiya, and N. Kinoshita: CIRP Ann. 33 (1984) 105.

18 S. Matsuo and Y. Adachi: Jpn. J. Appl. Phys. 21 (1982) L4.

19 M.Ishii, Y. Hirose, T. Satoh, T. Ohwaki, and Y. Taga : J. Vac. Sci. Technol. A 15 (1997) 820.

20 T. Itoh, T. Tsurushima, K. Yata, and I. Ohdomari: Ion Implantation (SHOKODO, Tokyo, 1976) (in Japanese).

21 SRIM2013: http://www.srim.org (accessed September 2021).

22 N. Kawasegi, N. Morita, S. Yamada, N. Takano, T. Oyama, S. Momota, J. Taniguchi, and I. Miyamoto: Appl. Surf. Sci. 253 (2007) 3284.

23 K. Eriguchi Y. Nakakubo, A. Matsuda, Y. Takao, and K. Ono: Jpn. J. Appl. Phys. 49 (2010) 056203.

24 A. Matsutani and A. Takada: Jpn. J. Appl. Phys. 49 (2010) 127201.

25 A. Matsutani and A. Takada: Sens. Mater. 27 (2015) 383.

26 M. Tohnishi and A. Matsutani: Sens. Mater. 33 (2021) 569. 
